Review

\title{
Common Virulence Factors and Tissue Targets of Entomopathogenic Bacteria for Biological Control of Lepidopteran Pests
}

\author{
Anaïs Castagnola ${ }^{1}$ and S. Patricia Stock ${ }^{2, *}$ \\ 1 Center for Insect Science, University of Arizona, 1007 E. Lowell Street, Tucson, AZ 85721, USA; \\ E-Mail: anais@email.arizona.edu \\ 2 Department of Entomology, University of Arizona, 1140 E. South Campus Dr., Tucson, \\ AZ 85721, USA \\ * Author to whom correspondence should be addressed; E-Mail: spstock@email.arizona.edu; \\ Tel.: +1-520-626-3854; Fax: +1-520-621-1150.
}

Received: 22 September 2013; in revised form: 13 December 2013 / Accepted: 17 December 2013 / Published: 6 January 2014

\begin{abstract}
This review focuses on common insecticidal virulence factors from entomopathogenic bacteria with special emphasis on two insect pathogenic bacteria Photorhabdus (Proteobacteria: Enterobacteriaceae) and Bacillus (Firmicutes: Bacillaceae). Insect pathogenic bacteria of diverse taxonomic groups and phylogenetic origin have been shown to have striking similarities in the virulence factors they produce. It has been suggested that the detection of phage elements surrounding toxin genes, horizontal and lateral gene transfer events, and plasmid shuffling occurrences may be some of the reasons that virulence factor genes have so many analogs throughout the bacterial kingdom. Comparison of virulence factors of Photorhabdus, and Bacillus, two bacteria with dissimilar life styles opens the possibility of re-examining newly discovered toxins for novel tissue targets. For example, nematodes residing in the hemolymph may release bacteria with virulence factors targeting neurons or neuromuscular junctions. The first section of this review focuses on toxins and their context in agriculture. The second describes the mode of action of toxins from common entomopathogens and the third draws comparisons between Gram positive and Gram negative bacteria. The fourth section reviews the implications of the nervous system in biocontrol.
\end{abstract}


Keywords: Photorhabdus; Bacillus thuringiensis; virulence factors; toxins; neurobiology; Mcf; Tc; Cry

\section{Introduction}

For many decades, naturally occurring microbial insect pathogens, including bacteria, fungi, microsporidia, protists, viruses, and nematodes have been considered as non-chemical alternatives for suppression of insect pests [1-3]. Positive attributes such as their high specificity and less damage to non-target fauna and flora has certainly contributed to the consideration in management practices of agricultural and forest insect pests [4].

Of all entomopathogens, bacteria have been the most extensively used organisms to date. Indeed, Bacillus thuringiensis (Bt) (Firmicutes: Bacillaceae), originally discovered in 1901 by Ishiwata [5] and later rediscovered by Berliner [6], has been the most studied and broadly used in microbial control. In particular, the discovery that Bt spore-associated toxins are extremely virulent and can persist in the environment with high potency, prompted the development of bacterial spray formulations [7] and transgenic plants expressing bacterial toxins [8,9]. Advancements in the characterization of bacterial pathogens including purification and culturing methods, molecular identification of virulence factors, and whole genome characterization and comparisons have prompted the discovery of novel pest management tools. In this vein, insecticidal molecules expressed and secreted by various entomopathogenic bacteria have been targeted for genetic manipulation to enhance toxicity $[10,11]$.

Recently, other insect pathogenic bacteria with modes of action similar to Bt have been hailed as agriculturally relevant [12]. Certainly, insect pathogenic bacteria of diverse taxonomic groups and phylogenetic origin have been shown to have striking similarities in the virulence factors they produce. [13]. Bacterial virulence factors are often encoded on mobile genetic elements, such as plasmids and bacteriophages, and can easily be spread through horizontal gene transfer. The discovery that both Gram-negative and Gram-positive bacteria produce analogous insect-specific toxins infers history of gene transfer between these organisms [14]. For example, Photorhabdus luminescens (Proteobacteria: Enterobacteriaceae), the bacterial symbiont of the entomopathogenic nematode Heterorhabditis bacteriophora (Rhabditida: Heterorhabditidae), has been shown to have similar virulence factors to that of $\mathrm{Bt}$ [15].

Herein, we review the commonalities between virulence factors produced by entomopathogenic bacteria. Special emphasis is placed on those with potential for control of lepidopteran pests. Additionally, we discuss and propose novel tissue targets of virulence factors for their potential application in pest management.

\section{Toxins Produced by Entomopathogenic Bacteria}

Insecticidal toxins used in agriculture are predominantly from Gram-positive bacteria and derived mostly from Bacillus thuringiensis. Foliar sprays containing B. thuringiensis represent an organic alternative to synthetic foliar sprays. Transgenic plants expressing Cry toxins are now viewed as an overwhelming ecological success [16]. 
Entomopathogenic Gram-negative bacteria also produce toxins. Based on their targeted tissues, they can be categorized into three types (a) neurotoxins; (b) digestive toxins; and (c) cytotoxins. Members in the Enterobacteriaceae such as Photorhabdus, Xenorhabdus, Serratia, and Yersinia spp. produce insecticidal toxins with oral toxicity similar to that of Bt toxins, but have not yet been fully utilized.

This section describes the virulence factors associated with both Gram-negative and Gram-positive bacteria as well as their mode of action.

\subsection{Insecticidal Toxin Genes Produced by Gram Positive Bacteria}

\subsubsection{Bacillaceae}

Bacillus spp.: Within this genus three species, B. thuringiensis, Bacillus cereus, Bacillus anthracis are the most widely studied taxa in terms of insecticidal toxins. Recent phylogenetic studies based on 16S and 23S rRNA sequence data consider B. thuringiensis, together with B. cereus, B. anthracis and Bacillus mycoides (Firmicutes: Bacillaceae) nearly identical. However, their unique pathogenicity properties and the diverse modes of actions of their insecticidal toxins (Table 1) support their distinctiveness, giving each separate species names [13].

Bacillus thuringiensis is a phylloplane and soil-dwelling bacterium that is aerobic and endospore-forming. It has been isolated from many insect carcasses and a few plants, where it has been reported as an endophyte. Upon sporulation, B. thuringiensis forms crystals of proteinaceous insecticidal $\delta$-endotoxins, called crystal proteins or Cry proteins, which are encoded by cry genes [17]. The Cry toxins, are insecticidal to many insect orders including Lepidoptera, Diptera [18,19], Coleoptera [20], and Hymenoptera [21], and also have activity against nematodes [22,23]. Upon ingestion by Lepidoptera larvae, Cry protoxins are first solubilized by the alkaline $\mathrm{pH}$ of the gut, then proteolytically activated by proteases. The insecticidal form of these toxins has been shown to bind to specific receptors on the columnar cells of the midgut epithelium causing pore formation and midgut cell death. Cry toxins are commonly classified as gut poisons, as they compromise the epithelial-hemocoel layer and ultimately lead to starvation and/or septicemia and larval death [24]. Cry toxins bind, form pores, and damage midgut epithelial goblet cells in mixed midgut cell cultures [25] and in vivo [26] and have also been shown to bind to the insect's peritrophic matrix [27]. The Cry toxins from $B$. thuringiensis are almost exclusively considered digestive toxins; however, they have homology to neurotoxins and effect diverse tissues of lepidopteran larvae. They have been shown to kill larval neurons of the cerebral ganglia in vitro [28], invade liposomes causing morphological changes to lipid bilayers in vitro [29], initiate apoptosis-like pathway in ovary-derived cells expressing a Bt receptor [30], and bind ATP-binding cassette (ABC) transporters [31]. In this respect, mutated $\mathrm{ABC}$ transporters are correlated with resistance to Bt toxins in domesticated silkworm, Bombyx mori (Lepidoptera: Bombycidae) [32], tobacco budworm, Heliothis virescens (Lepidoptera: Noctuidae) [33], diamond back moth, Plutella xylostella (Lepidoptera: Plutellidae), and cabbage looper, Trichoplusia $n i$ (Lepidoptera: Noctuidae) [34]. 
Table 1. Mode of action of entomopathogenic bacterial toxins with toxicity to lepidopteran larvae.

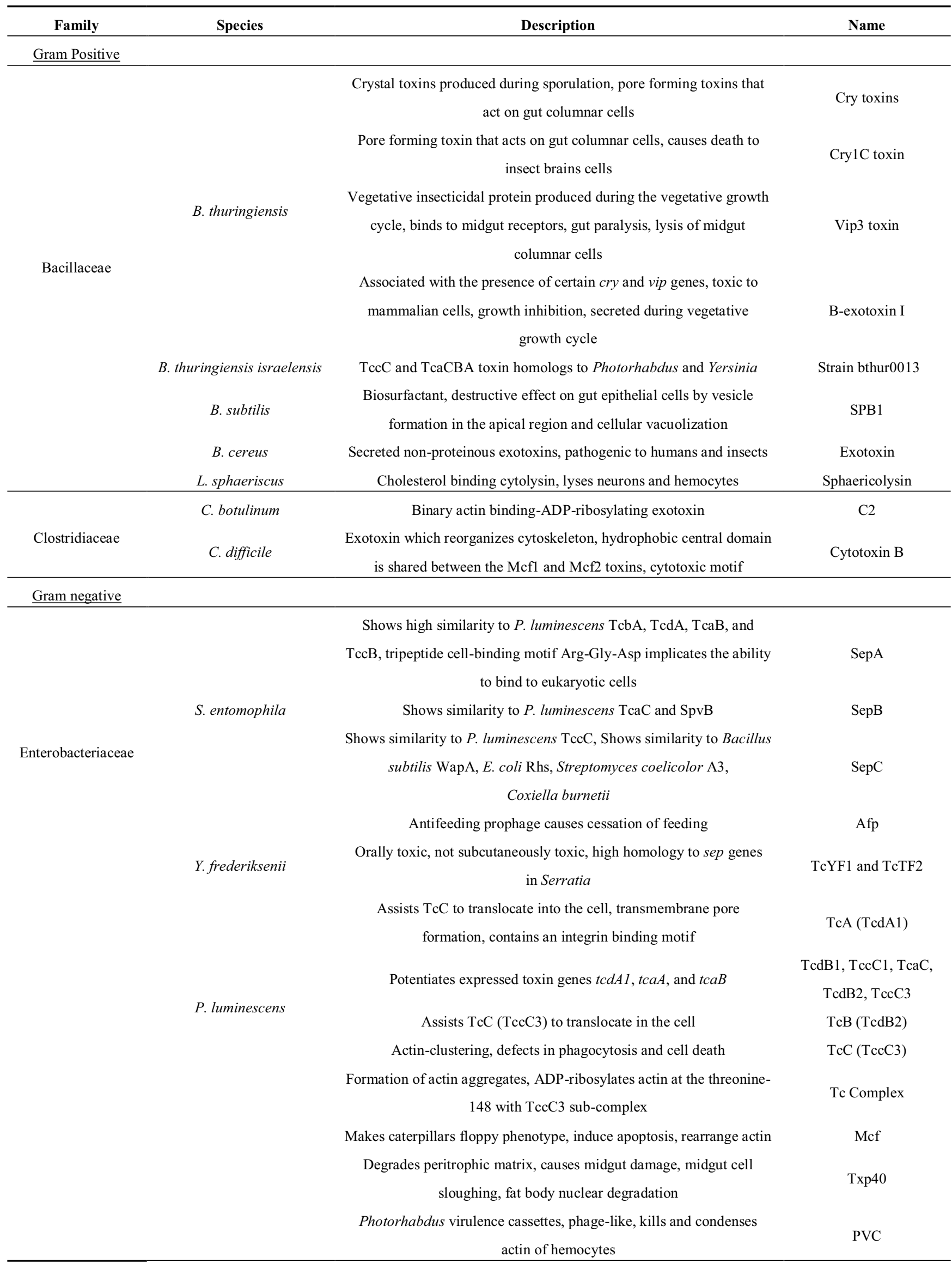


Table 1. Cont.

\begin{tabular}{|c|c|c|c|}
\hline Family & Species & Description & Name \\
\hline & & Primarily hemoplymph-based insecticidal activity & $\begin{array}{l}\text { pirA2B2, locus } \\
\text { plu4437-plu4436 }\end{array}$ \\
\hline & & Similar to Serratia-type hemolysins & phlBA operon \\
\hline & & Binds actin ADP-ribosylating, inhibits actin polymerization & Photox \\
\hline & & Midgut, intestinal sloughing & A24tox \\
\hline & & Fed to neonates and caused inhibitory growth & Xin \\
\hline & X. nematophila & From the cosmid CHRIM1, analogs to sep Serratia genes, oral toxicity & $\begin{array}{c}\mathrm{XptA} 1, \mathrm{XptA2}, \mathrm{XptB1} \\
\mathrm{XptC1}\end{array}$ \\
\hline & & $\begin{array}{l}\text { Alphaxenorhabdolysin triggers apoptosis in hemocyte cells, cytotoxic } \\
\text { and hemolysin effects, has analogs in Photorhabdus, P. entomophila, } \\
\text { P. syringae, Y. enterocolitica, and Proteus mirabilis }\end{array}$ & $\mathrm{xax} A B$ \\
\hline & & $\begin{array}{l}\text { High similarity to GroEL, injectable toxicity to G. mellonella, innate } \\
\text { immune response of increased phenoloxidase activity stimulated by } \\
\text { injection }\end{array}$ & HIP57 \\
\hline & & One gene in the xenocin operon with RNAse and cytotoxic activity & $\mathrm{xciA}$ \\
\hline \multirow[t]{15}{*}{ Pseudomonadaceae } & P. fluorescens & $\begin{array}{l}\text { Related to the Mcf from } P \text {. luminescens, hemolymph-based } \\
\text { insecticidal activity }\end{array}$ & Fit \\
\hline & & Regulators of Fit insect toxin expression for biocontrol & FitG \\
\hline & & & PSEEN2485, \\
\hline & P. entomophila & TccC-type toxins & PSEEN2697, \\
\hline & & & PSEEN2788 \\
\hline & & Tcc-C type toxins & PSEEN701, PSEEN702 \\
\hline & & & PSEEN3925, \\
\hline & & Exotoxins with hemolytic activity & PSEEN0968, \\
\hline & & & PSEEN3843 \\
\hline & & & PSEEN709, \\
\hline & & Linases & PSEEN1065, \\
\hline & & & PSEEN2195, \\
\hline & & & PSEEN3432 \\
\hline & P. syringae & Tcc-C type toxins & PSEEN701, PSEEN702 \\
\hline & & TcdB-type toxin & PSEEN1172 \\
\hline
\end{tabular}

Bacillus cereus has been mostly studied for its role in food contamination and human digestive food poisoning; however, this bacterium associates with soil and plants much like $\mathrm{Bt}$ [35]. As mentioned above, $B$. cereus and B. thuringiensis are two very closely related taxa, however they produce different types of toxins. Unlike $\mathrm{Bt}$, the endospore of $B$. cereus is not insecticidal. Both B. thuringiensis and B. cereus produce non-proteinous insecticidal exotoxins during their vegetative growth cycle. $\beta$-Exotoxin $I$ is produced by $B$. thuringiensis and a small, proteinous exotoxin is produced by B. cereus [36]. Although, B. cereus has been shown to grow and proliferate in the insect gut, this bacterium is mostly regarded as an opportunistic pathogen with the production of virulence factors that are most effective when titers are high. Entomopathogenic toxin genes have also been found in the genome of strain B. thuringiensis israelensis bthur0013, a member of the B. cereus sensu lato [37]. 
Other Bacillus species known to produce insecticidal components are Bacillus circulans (Firmicutes: Bacillaceae) and sphaeriscus (Firmicutes: Bacillaceae) (=Lysinibacillus sphaeriscus). Virulence factors produced by the former sp. have been shown to affect insects (mostly dipterans) and other invertebrates such as nematodes, and mollusks [38]. Sphaericolysin is a toxin produced during the vegetative growth cycle of L. sphaeriscus [39]. This toxin has heamoceolic toxicity toward Blattela germanica (Blattodea: Blattellidae) and Spodoptera litura (Lepidoptera: Noctuidae) [40].

\subsubsection{Clostridiaceae}

Clostridium spp.: Clostridium are anaerobic spore-forming bacteria and, similar to Bacillus, comprise over one hundred species. Similar to Bacillus, Clostridium spp. produce binary proteinous toxins that are proteolytically activated by serine proteases [41] (Table 1). For example, Clostridium bifermentans serovar malaysia produces larvacidal toxin proteins that are active against mosquitoes [42]. Clostridium perfringens (Firmicutes: Clostridiaceae) has an iota toxin which binds actin by ADP-ribosylation and has a C-domain structure similar to that of the vegetative insecticidal protein of Bt, VIP2, although this protein ultimately targets mammals [43]. The Clostridium difficile cytotoxin B is an exotoxin which causes the reorganization of cytoskeletons, similar to Mcf (Makes Caterpillars Floppy) toxins produced by Gram-negative P. luminescens (See Section 2.2). Moreover, they have a three domain structure consisting of receptor-binding, translocation, and one catalytic domain [44].

The actin binding $\mathrm{C} 2$ toxin of another Clostridium sp., C. botulinum, is a binary toxin with four domains of activation, pore formation, and receptor recognition. The $\mathrm{C} 2$ toxin is similar to the toxin complex, TccC3, produced by $P$. luminescens because they both have ADP-ribosylating activity and bind actin. One difference between these two toxins is that $\mathrm{TccC} 3$ forms a complex with other Tc toxins, TcdA1 and TccC3, and is therefore not binary. Although ADP-ribosylation occurs in both cases, TccC3 ribosylates at a threonine while $\mathrm{C} 2$ toxins ribosylate at arginine, dysfunctioning actin by inducing actin polymerization in the former and inhibition in the latter [45]. A toxin found in $P$. luminescens has an identical mode of action to that of $\mathrm{C} 2$ toxin. The translated product of the plu0822 gene, termed Photox toxin, stops actin polymerization by targeting an arginine with ADP-ribotransferase activity [46].

\subsection{Insecticidal Toxin Genes Produced by Gram Negative Bacteria}

\subsubsection{Enterorbacteriaceae}

Photorhabdus spp.: Until now three species have been identified within this genus: P. luminescens, Photorhabdus temperata and Photorhabdus asymbiotica [47]. All Photorhabdus species are mutualistically associated with insect parasitic Heterorhabditis nematodes. However, P. asymbiotica has also been found associated with skin injuries in human patients [48]. This bacterium is currently considered an emerging human pathogen model system [49]. Unlike B. thuringiensis, Photorhabdus spp. are facultative anaerobes and cannot live freely in the soil environment. These bacteria are vectored by the nematodes and together they form an insecticidal complex that kills the insect and use the carcass for reproduction and nutrition. Once delivered by the nematodes in the insect hemocoel, the bacteria first evade the insect immune system and then produce toxins which kill the insect and break 
down insect epithelial tissues. The Photorhabdus genome contains a multitude of pathogenicity islands with an abundance of toxin genes [50]. The major virulence factors characterized so far consist of the $m c f 1$ and $m c f 2$ (makes caterpillars floppy) genes, the tc (toxin complex) genes, Pir (Photorhabdus insect related) operon, and a multitude of virulence factors associated with the Photorhabdus virulence cassettes (PVC) (Table 1) [51].

The Mcf toxins are known to both rearrange actin cytoskeletons and induce apoptosis in both hemocytes and epithelial tissue, resulting in an abundance of tissue damage. The intensity of the tissue damage is so great that there is a complete loss of turgor pressure throughout the infected insect [52].

The Tc proteins, similar to Bt Cry toxins, are orally toxic compounds that have been discovered to be insecticidal to a wide range of insect taxa including Coleoptera, Lepidoptera, and Hemiptera. It has been shown that $P$. luminescens is highly pathogenic when injected into lepidopteran hosts such as the African cotton leafworm, Spodoptera littoralis (Lepidoptera: Noctuidae), and P. xylostella. The oral toxicity of the Tc proteins is peculiar because Photorhabdus are delivered directly into the hemocoel of the target insect. Furthermore, the Tc proteins are active in the lumen side of the insect's midgut epithelium and not in the basal side of this tissue, which would be the expectation for a hemocoel-initiating pathogen [53].

Pir proteins are other Photorhabdus toxins that have been identified to have hemolymph [54] and oral [55] toxicity. The Pir proteins have homology to a neurotoxin commonly called leptinotarsin [55-57] and are binary [51]. The binding and destructive effects on neural tissue could be a major factor in toxicity when Photorhabdus are injected into susceptible insects.

It can be speculated that there are many more toxins yet to be characterized from the Photorhabdus genome which are responsible for hemolymph-based toxicity. The Txp40 protein has been identified in 59 different strains of both Photorhabdus and Xenorhabdus. It has injectable toxicity to many lepidopteran insects including the greater wax moth, Galleria mellonella (Lepidoptera: Pyralidae), Indian meal moth, Plodia interpunctella (Lepidoptera: Pyralidae), corn earworm, Helicoverpa armigera (Lepidoptera: Noctuidae), and the Dipterans such as the Australian sheep blowfly, Lucilia cuprina (Diptera: Calliphoridae) [58]. A txp40 gene, when expressed by E. coli, has also been shown to be insecticidal to P. xylostella [59]. The Txp40 protein is involved in causing damage to both the insect midgut and the fat body and has also been shown to exhibit cytotoxicity in vitro in dipteral and lepidopteran cell lines [58].

Xenorhabdus spp.: Similar to Photorhabdus, bacteria in this genus are also non-free-living, though they are symbiotically associated with nematodes in the genus Steinernema [60]. Similar to Heterorhabditis, Steinernema nematodes also play a key role in vectoring these bacteria from one insect host to another. Xenorhabdus also produce a large number of insecticidal toxins to help them garner nutrients from the insect hosts (Table 1). One example is a toxin from Xenorhabdus nematophila (Proteobacteria: Enterobacteriaceae) called A24tox. A24tox is a $42 \mathrm{kD}$ protein that has been shown to kill G. mellonella and H. armigera. This toxin has a hypothetical homolog in Photorhabdus but has no significant matches outside of this group [61]. Another example is the xenocin operon. The xenocin operon consists of two genes, $x$ ciA and $x \operatorname{imB}$. When expressed, these molecules are secreted by the flagellar type II secretion pathway. Xenocin, the $x c i A$ gene, has RNAse activity and cytotoxicity. The immunity protein co-expressed in the xenocin operon has antimicrobial effects killing competing microbes in insect larvae [62]. 
The $x p t$ gene products from $X$. nematophila have oral insecticidal activity to different lepidopteran larvae based upon how the differentially expressed xpt genes interact with each other. In this respect, the translated products of Tc genes are similar to the Tc proteins from Photorhabdus. The Tc gene products can be categorized into toxins and potentiators. Potentiators synergize with their Tc toxin counterpart for full insecticidal activity [53]. When xptA1, xptA2, xptB1, and xptC1 genes are expressed in Escherichia coli and are fed to larvae, they confer oral insecticidal toxicity to various lepidopteran spp. including: cabbage butterfly, Pieris brassicae (Lepidoptera: Pieridae), white butterfly, Pieris (Lepidoptera: Pieridae), and H. virescens. Interestingly, when the interactions of all four genes are separated from each other their insecticidal toxicity is different. For example, E. coli expressed $x p t A 1, x p b t B 1$, and $x p t C 1$ are needed to be insecticidal toward $P$. rapae and $P$. brassicae. The addition of xptA2 and the removal of $x p t A 1$ is all that is needed for insecticidal toxicity toward $H$. virescens. Thus, different combinations of the xpt E. coli lysates show different insecticidal specificities to different lepidopteran larvae [63]. The intracellular Xin toxic protein from X. nematophila has also been demonstrated to have an inhibitory growth effect on cotton bollworm, Helicoverpa (Lepidoptera: Noctuidae), after ingestion with artificial diet incorporating the Xin protein [64].

The $x a x A B$ genes from $X$. nematophila expressed in $E$. coli induce apoptosis when incubated with hemocytes derived from $S$. littoralis. Additionally, the order in which Xax toxins (XaxA and XaxB) are added to cells in vitro affects their toxicity [65]. This is similar to xpt and tc genes that are expressed in E. coli.

Xenorhabdus bacteria also produce an insecticidal protein called HIP57 that have high similarity to chaperonins like GroEL produced by E. coli. GroEL chaperonins have been shown to help proteins fold from non-native to native structures [66]. Moreover, they help combat problems such as aggregation when nascent proteins have hydrophobic residues exposed before reaching a fully folded native state [67]. HIP57 has been shown to have injectable toxicity to G. mellonella. The insecticidal property of HIP57 is a novel function for the GroEL superfamily of proteins. Moreover, an innate immune response of increased prophenoloxidase activity is stimulated by HIP57 injection [68].

Serratia spp.: These bacteria often exist as endophytes possessing fungicidal properties, but can also associate with insects [69] and nematodes [70,71] in a facultative manner. Genome studies have found several insecticidal genes in the Serratia genome (Table 1). Other Serratia sp. are responsible for causing amber disease in grass grubs, Costelytra zealandica (Coleoptera: Scarabaeidae) [72]. Contrastingly, Serratia marcescens (Proteobacteria: Enterobacteriaceae) infects other host such as poorly reared $H$. virescens [73]. The pADAP plasmid from Serratia entomophila contains the genes $\operatorname{sep} A, \operatorname{sep} B$, and $\operatorname{sep} C$. These genes are similar to the Tc genes described in P. luminescens and the $x p t$ genes identified from $X$. nematophila. There is no need for the entire pADAP plasmid to be associated with the sep genes for amber disease to occur and cause death. However, when the sep genes are expressed in E. coli without the entire plasmid, the scarab beetles do not cease feeding [74] which is one symptom of amber disease. The virulence factor associated with pADAP that causes cessation of feeding in amber disease is the anti-feeding prophage (Afp) [75]. Therefore both the sep genes and Afp are needed for full virulence of Serratia in grass grubs.

Yersinia spp.: Members of this genus are facultative anaerobes. In particular, Yersinia pestis the causative agent of bubonic disease (aka plague) is associated with fleas, humans and rodent intermediates. Two other species which are pathogenic to humans are Yersinia enterocolitica and 
Yersinia pseudotuberculosis often causing diarrheal disease and fever with inflammation, respectively. Yersinia entomophaga (Proteobacteria: Enterobacteriaceae), Yersinia frederiksenii [76], which can cause disease in grass grubs, Y. enterocolitica [77], Y. pseudotuberculosis, Yersinia mollaretii (Proteobacteria: Enterobacteriaceae) [78] and Y. pestis [79] have insecticidal genes of the Tc super family.

The pathogenicity island YAPI ${ }^{\mathrm{Ye}}$ of $Y$. enterocolitica strain W22703 contains the homologues tcaA, $t c a B$, tcaC, and $t c c C$ and is insecticidal to the tobacco hornworm, Manduca sexta (Lepidoptera: Sphingidae), when fed orally; a tcaA mutant of the same Y. enterocolitica strain lost insecticidal lethality to M. sexta [80]. Two Y. enterocolitica strains, W22703 and WA314, were shown to have nematocidal activity against $C$. elegans when the strains contained TcaA, though the $E$. coli strain DH5 $\alpha$ expressing TcaA clones did not cause pathogenicity in C. elegans, implicating additional virulence factors are necessary for full nematicidal activity [81]. The pathogenicity island of Y. entomophaga, termed PAI ${ }^{\mathrm{Ye} 96}$, is composed of insecticidal chitinases and Tc components that cause virulence to C. zealandica. Liquid culture supernatants of $Y$. entomophaga were also shown to be insecticidal to the redheaded cockchafer, Adoryphorus couloni (Coleoptera: Scarabaeoidae), blackheaded pasture cockchafer, Acrossidius tasmaniae (Coleoptera: Scarabaeidae), and P. xylostella. In the case of $P$. xylostella, initial apical swelling of gut columnar cells occurred after ingestion of purified Tc from $Y$. entomophaga, followed by complete dissolution of the gut lining [82].

\subsubsection{Pseudomonadaceae}

Pseudomonas spp.: The renowned anti-fungal properties of root-associated bacteria of the genus Pseudomonas have been widely used for crop protection and further investigated for viable natural products in both agriculture and medicine. The insecticidal properties (Table 1) of Pseudomonas entomophila, Pseudomonas syringaeand Pseudomonas fluorescens were discovered subsequently.

Pseudomonas fluorescens insecticidal toxin, or Fit, is an insecticidal proteinous toxin that causes complete loss of turgor pressure and melanization. This toxin has hemocoel-based toxicity in M. sexta, and G. mellonella [83]. Based on comparisons with Pseudomonas strains not expressing the Fit toxin, Fit has been shown to be orally toxic to S. littoralis, H. virescens, and P. xylostella. Pseudomonas chlororaphis (Proteobacteria: Pseudomonadaceae) also expresses a Fit toxin and has oral insecticidal activity [84]. A factor of $P$. fluorescens which correlates to insecticidal activity is the global regulator gene gacA. The expression of this gene influences components of the type VI secretion system [85] and gacA mutants do not have full insecticidal action [84].

Pseudomonas entomophila destroys gut cells of the common fruit fly, Drosophila melanogaster (Diptera: Drosophilidae). Based on GC content analysis and the presence of transposases, three prophages, a pyocin-like phage, and a lambdoid phage in the genome, some insecticidal genes of $P$. entomophila were likely acquired through lateral gene exhange. This amount of gene acquisition is less than detected in the genomes of Pseudomonas putida (Proteobacteria: Pseudomonadaceae) and Pseudomonas syringae (Proteobacteria: Pseudomonadaceae). Although the genome of $P$. syringae does contain $t c$ homologs, Tcc and TcdB, similar to those seen in the genome of $P$. fluorescens [86]. Other insecticidal components of P. fluorescens, besides the Fit toxin, consist of three TccC toxins, lipases, and exotoxins with hemolytic activity. 


\section{Insecticidal Genes and Toxins Shared by Entomopathogenic Bacteria}

The insecticidal components common between different entomopathogenic bacteria often originate from bacteria of widely different life histories. Some bacteria require other organisms such as nematodes or arthropod vectors for their dissemination and introduction to an insect host while others are free-living. This section summarizes the common hypotheses surrounding the issue of why so many insecticidal genes are shared between Gram-positive and Gram-negative bacteria.

\subsection{Bacillus and Clostridium}

\subsubsection{A Shared Environment Promotes Gene Transfer}

Although Bt is a highly potent insect pathogen in nature, it is rarely associated with diseased insect populations [87]. This is a singular situation for such an effective entomopathogen with specific insect toxins. In this respect, it has been hypothesized that the origin of toxin virulence factors in Bt more likely did not originate through its relationship with insects but through plasmid acquisition $[37,88,89]$. Interestingly, Bt toxins are reported to be synergistic with other insect pathogens, like Serratia, which exists as both a pathogen and symbiont of insects [90]. The ubiquity of Bt where potential insect hosts exist or where insect-associated organisms occur, could have resulted in the acquisition of insecticidal genes.

It is widely accepted that in nature plasmids can be transferred between bacteria [91], however, there is also evidence for gene transfer between organisms of widely different taxa [92-96]. In reference to this, it can be speculated that transfer of insecticidal genes to $\mathrm{Bt}$ genome could have occurred when this bacterium occupied the same environment as an insect host. For example, the transfer of plasmid pX016::Tn5401 between mosquitoes and a Bacillus species could have occurred when both organisms lived in the same river [97]. Similarly, it is proposed that the virulence factors of $B$. anthracis and the $\delta$-endotoxins genes of $\mathrm{Bt}$, which are on a single plasmid, were recently acquired through horizontal gene transfer [37].

Studies have shown that Clostridium spp., Bacillus spp., and P. luminescens have analogs of the $t c$ gene family. In a mass screening of $B t$ strains, 17 out of 81, contained $t c c C$ gene analogs [98]. Moreover, Mcf toxins are also shared between Clostridium spp. and P. luminescens. Specifically, the exotoxin from $C$. difficile called cytotoxin $\mathrm{B}$, that causes cytoskeletal reorganization, has a similar mode of action to that of $P$. luminescens toxins Mcfl and Mcf2. Specifically, the hydrophobic central domain to $C$. difficile toxin B is the portion shared between the Mcfl and Mcf2 toxins of P. luminescens. Both of these toxins are known to have injectable insecticidal activity and have a well characterized cytotoxic motif [51]. Also, the $\mathrm{C} 2$ toxins of $C$. botulinum are known to bind actin like Tc toxins. The $t c$ genes can be found in various strains of Bt including B. thuringiensis israelensis bthur0013. In bthur0013 there is an operon with Tc homologs, TccC and TcaCBA, similar to those found in Photorhabdus and Yersinia spp. [37]. 


\subsection{Photorhabdus and Xenorhabdus}

\subsubsection{Virulence Factors and Specificity in a Mutualistic Relationship}

Major similarities exist at the molecular level between Photorhabdus and Xenorhabdus demonstrated by their insect pathogenic behavior and expression of virulence factors. Secreted proteins and toxins of Photorhabdus and Xenorhabdus have been shown to play a key role in the dual lifestyle of these bacteria - that is, being avirulent when associated with their nematode hosts and switching to virulence after accessing an insect host. Photorhabdus and Xenorhabdus secreted proteins play multiple roles during the lifecycle of these bacteria. For example, some are insect-directed virulence factors while others serve as antibiotics to protect the insect cadaver from microbial invaders. Also, chitinases have been found in both Xenorhabdus and Photorhabdus that have anti-mycotic activity [99]. Two alkaline metalloproteases have been identified from Photorhabdus, PrtA and PrtS, both of which inhibit insect antibacterial factors [100]. The secretion of proteins that are both virulent to insects and promote nematode association may be specific to this group of bacteria due to their unique mutualistic relationship.

Photorhabdus and Xenorhabdus have similar virulence genes and both share a portion of their lifecycle with nematodes. Although their genomes are very similar, strains of Xenorhabdus differ from Photorhabdus strains by existing as a monoculture in Steinernema nematodes whereas Heterorhabditis nematodes may contain many different strains of Photorhabdus at once [101,102]. It is hypothesized that the differences between the genomes of Photorhabdus and Xenorhabdus are actually strategies which assist bacteria-nematode association and mutualism.

The Photorhabdus genome has higher plasticity with many transposable elements while Xenorhabdus lacks this trend; thereby it has limiting genetic variability [101]. The molecular mechanisms that promote plasticity in Photorhabdus may explain why so many of its virulence factors have orthologs in other organisms. Other genes which regulate the association of Photorhabdus and Xenorhabdus with their insect host have been reviewed and explored demonstrating that, although both Xenorhabdus and Photorhabdus have similar genomes, their strategies to avoid the host immune system, cause pathogenicity, and promote mutualism, differ [103].

The Tc toxins are a superfamily of insecticidal pore-forming toxin proteins that were first identified in P. luminescens [104]. The Tc toxins are found in numerous amounts in other organisms and have been further addressed throughout this section. Cloned TcdA, TcdB, and TccC confer oral toxicity [105] and transgenic plants expressing TcdA alone are insecticidal [106]. It has been shown that each subunit of this toxin can have its own insecticidal action [107] and, interestingly, they confer higher toxicity when combined with other Tc subunits [53]. Tc protein subunits are grouped into three categories: "A", "B", and "C". The Tc Bs and Tc Cs are known to make the Tc As more toxic [108].

The Xax proteins are found in $X$. nematophila and $P$. luminescens. The xax genes from $X$. nematophila when expressed in E. coli have hemocoel-based toxicity acting directly on hemocyte cells. Xax peptides are also found in the P. luminescens hemolysin gene designated plu1962. The two loci from the genome of P. luminescens strain TT01 called plu1961 and plu1962 seem to be co-transcribed. This is interesting because the order in which Xax toxins (XaxA and XaxB) are added to cells affect their toxicity [65]. 
Xenorhabdus xpt genes exist on a pathogenicity island like the tc genes of Photorhabdus and have been demonstrated to confer oral insecticidal activity when cloned into E. coli and fed to lepidopterans. $T c$ genes are associated with phage elements and $x p t$ genes were likely introduced into their pathogenicity island on transposons [101]. Although not all on a pathogenicity island, Xpt, Tc, Xax, and Sep toxins are similar because different combinations of their clones effects their toxicity when fed to insects [63]. It has been demonstrated that the pathogenicity islands of strains of Xenorhabdus are nearly identical. This indicates that presence of this pathogenicity island corresponds to an evolutionary advantage or increased fitness. Additionally, it is a hotspot for gene integration or acquisition. There is also evidence supporting the belief that virulence genes were acquired after the original pathogenicity island was integrated into the genome [101].

\subsubsection{Novel Targets in the Hemolymph}

The genomic organization of the Pir operon of both P. luminescens and asymbiotica consists of a promoter region, PirA, and PirB; Pir toxin [50,54]. It is unknown how PirA and PirB are differentially expressed when targeting an insect host. Pir toxin is a binary protein that may have an interesting mode of action based upon its homology profile. PirB is homologous to $\mathrm{Bt} \delta$-endotoxins in the pore-forming domain and leptinotarsin. Leptinotarsin has been purified from the Colorado potato beetle, Leptinotarsa decemlineata (Coleoptera: Chrysomelidae) and has homology to juvenile hormone esterase which is a developmentally regulated protein. Pir toxin does not disrupt insect metamorphosis $[54,56,57]$. Leptinotarsin is a neurotoxin that stimulates release of acetylcholine at the presynaptic nerve terminal $[109,110]$. Interestingly, it has been reported that supernatants of $P$. luminescens cultures upregulate insect nervous system genes [111]. The mode of action of Pir toxin and its potential relationship to the insect nervous system is yet to be elucidated.

There are phage-related-loci in both Serratia and Photorhabdus. In Serratia the phage-related loci are pADAP which causes a decreased feeding reaction in infected insects [112]. The phage-related loci of Photorhabdus (aka PVC) confers hemolymph-based injectable toxicity on Galleria larvae. The target of this virulence factor is hemolymph-circulating phagocytes [113]. Besides the PVC, there are cycle-inhibiting factors (Cif) produced by P. luminescens. Although it is unknown how Cif interacts with an insect host, when the cif gene is electroporated into Spodoptera dervied Sf9 cells they undergo apoptosis and cell cycle arrest [114]. Furthermore, there is a secretion system, termed the type III secretion system or T3SS which is similar to the one characterized in Yersinia where effector proteins are translocated through T3SS into host cells [115]. In Yersinia the effector protein YopT is a cytotoxic cystein protease whereas the homolog in P. luminescens, called LopT, has been shown to prevent phagocytosis [116].

\subsection{Serratia and Yersinia}

\subsubsection{Presence of Insecticidal Genes}

Both Yersinia and Serratia share Tc homologs. Analysis of the sep genes from Serratia showed that they are a cluster associated with pADAP and are a part of a horizontally mobile region. The sep insecticidal toxin genes from $S$. entomophila and $S$. proteomaculans occur in $Y$. frederiksenii. The 
Y. frederiksenii sep-like genes were termed $t c Y F 1$ and $t c Y F 2$ and have correlating high percent identity to sepA and sepB genes [76]. In Y. pestis, toxin complexes A, B, and C (TcaA, TcaB, and TcaC) are termed yitA-C. There are insecticidal regions of homology between $P$. luminescens, $Y$. pestis, and Salmonella genes termed $t c d B 1$, yitC, and $s p v B$, respectively. The Salmonella gene $s p v B$ is an effector of the T3SS secretion system [117]. Different Yersinia species have a common genomic backbone. When analyzing the presence of insecticidal genes between all Yersinia species the $t c$ operons have been inserted into a common region of the greater Yersinia backbone [118].

\subsubsection{The Presence of Insecticidal Toxins May Increase Pathogenicity and Infectivity}

The discovery of insecticidal components produced by $Y$. pestis is interesting because these bacteria require insect vectors (such as fleas) for human infectivity. Studies conducted by Spinner et al. 2012 have shown that two Tc proteins of this bacterium, YitA (TcaA-like) and YipA (TccC-like), are highly expressed when the bacteria are inside the flea. However, it has been shown that deletion of these two toxins does not prevent flea infection [119]. The presence of the $t c$ genes in Yersinia spp. suggests that insects are a natural host of these bacteria. Studies have shown that different Yersinia strains tested for oral toxicity against $M$. sexta cause higher mortality when the strains have the toxin complex pathogenicity island; however, their insecticidal activity showed no difference when they were subcutaneously injected into G. mellonella larvae [78].

The high similarity of Tc proteins in various strains of $Y$. pestis suggest that they may have similar roles in infectivity of fleas compared to Y. psuedotuberculosis where Tc proteins are less conserved [120]. However, Tcs of Yersinia spp., which are pathogenic to humans (Y. pestis, Y. pseudotuberculosis, and $Y$. enterocolitica), seem to play a differential role in mammal infectivity. There is differential specificity between the Tcs obtained from $Y$. pseudotuberculosis and $Y$. pestis on human epithelial cells. The TcaA from $Y$. pseudotuberculosis caused human-derived enterocytes to display actin ruffles and increased vacuolization. The TcaA from $Y$. pestis causes multinuclei formation. The TcaA from $P$. luminescens does not affect the actin of mouse-derived cells [53]. This level of specificity suggests TcaC of the insect toxin complex assists in human pathogenicity [121]. In Y. enterocolitica, an intestinal pathogen to humans, $t c$ genes have been shown to assist in gut colonization of mice and have higher prevalence in more virulent strains of $Y$. enterocolitica [77].

The toxins of different entomopathogens may assist increased pathogenicity to target insect populations. Jeong et al. showed that $S$. marcescens produces insecticidal oral toxins [122]. Interestingly, there is a synergistic insecticidal effect between $S$. marcescens chitinases [123] and Bt Cry1Ac toxin [90]. There are also synergistic effects between Bt Cry1C and the supernatant of S. marcescens to tobacco cutworm, Spodoptera litura (Lepidoptera: Noctuidae), but not cabbage moth, Mamestra brassicae (Lepidoptera: Noctuidae), P. xylostella, or the smaller tea tortrix, Adoxophyes honmai (Lepidoptera: Tortricidae) [124]. The insecticidal genes of Bt and Serratia may be able to work in synergism with each other in nature.

\subsection{Pseudomonas}

Pseudomonas fluorescens has both insecticidal and anti-mycotic properties. The virulence factor, Fit protein toxin, identified in $P$. fluorescens has been shown to have insecticidal properties and based 
upon homology, the Mcf proteins identified from $P$. fluorescens are suspected to have similar modes of action to that of Fit (See Section 2.2.1). When Fit or Mcf are ingested by lepidopteran larvae the toxin causes complete loss of turgor pressure and the characteristic "floppy" phenotype [83,84].

Another Pseudomonas species, P. entomophila, lacks the characteristic T3SS which most insecticidal bacteria possess to inject effector molecules into their host [125]. The virulence factors associated with $P$. entomophila have been shown to cause death of gut cells, suggesting an oral route for toxicity [126]. Many other insecticidal virulence factors have been identified in P. entomophila, some of which are the characteristic Tc analogs associated with a gene acquisition event [86].

\section{Neurobiology of Hemolymph-Based Toxicity}

This section summarizes the current knowledge of hemolymph-based toxicity caused by various entomopathogenic bacteria in relation to neurobiology of insect hosts. We also discuss potential application of this knowledge for use in the management of lepidopteran pests.

\subsection{Neurotoxins and Their Application in Pest Management}

Synthetic pesticides are the most widely accepted strategies for insect pest management. Most of the synthetic pesticides, such as organophosphates, pyrethroids, and phenylpyrazoles, target the nervous system of insects. When synthetic pesticides are applied as foliar sprays or used in urban settings they have the potential to persist in the environment with deleterious effects [127,128]. Furthermore, these insecticides lack pest specificity and promote development of pest resistance [129-131]. Synthetic pesticide resistance leads to a problem often referred to as the pesticide treadmill, meaning that the more often a pesticide is used, the more potent and highly concentrated a pesticide must be for efficacious future use [132].

The lack of specificity of synthetic pesticides results in similar toxic effects between insects, humans [133] and on other non-target organisms [134]. One example is the synthetic pesticide ingredient amitraz. This insecticide is an acaracide and an octopamine receptor agonist of the nervous system of invertebrates [135]. In the United States, it has been most commonly used to control ticks and fleas on dogs, mites on cotton, and insect pests on pear trees [136]. Amitraz also stimulates the a2-adrenoceptors of the human nervous system [137]. Some natural products used in organic agriculture have modes of action similar to synthetic pesticides despite their natural origins. For example, pyrethrum from chrysanthemums, Tanacetum cinerariifolium (Asterales: Asteraceae), have pyrethrins, chrysanthemates and pyrethrates with neurotoxic action similar to that of synthetic pyrethroids [138]. Another example is spinosyns from soil actinomycetes which disrupt acetyocholine neurotransmission [138]. One organic agricultural product with insect specificity is the azadirachtins class of organic chemicals, which is derived from the Indian neem tree, Azadirachta indica (Sapindales: Meliaceae), which block insect molting hormones thereby disrupting insect development [138].

One way to circumvent the damaging non-target effects of synthetic pesticides, which share common modes of action between humans and insects, is the consideration of naturally occurring entomopathogens and/or the toxins they produce [139]. For example, Bt foliar sprays are organic, have high specificity, and have negligible environmental impact compared to their synthetic counterparts [140]. Another alternative 
to synthetic pesticides is the use of toxins produced by mites, spiders, and other venomous organisms which also have been shown to have neurotoxic effects on insects [141]. Various studies have shown that some of the genes encoding these toxins can be expressed in transgenic plants and contribute to a decrease of the target insect population [142].

As mentioned, many neurotoxins have been discovered from invertebrates. For example, leptinotarsin, isolated and identified from the Colorado potato beetle, has been shown to disrupt the release of acetylcholine at the presynaptic nerve terminal of rat synaptosomes [109,110]. Although peptides of leptinotarsin have shown homology to both juvenile hormone esterase (JHE) of insects and Cry toxin of $\mathrm{Bt}$, there is no evidence that leptinotarsin has JHE activity. Because of the way proteinous neurotoxins interact and disrupt neural tissue function, they can be used to study the physiological consequences of the nervous system dysfunction [143]. Understanding their mode of action and interaction with the insect nervous system can make them a powerful tool with application in insect pest management.

\subsubsection{Insect Paralysis Caused by Bt}

Once Bt Cry toxins are ingested by lepidopteran larvae a number of effects concurrent to toxicity occur including paralysis. Paralysis is such a predominant characteristic that early studies reported paralytic effects caused by $\mathrm{Bt}$ as a preliminary way to discriminate among different insecticidal Bacillus species and strains [144]. Paralysis induced by Bt can be categorized by insect type. Type I insects are described by the symptom of whole body paralysis. The larvae have been described as becoming inactive causing them to fall off their host plant (Table 2). This has been demonstrated to be caused by increased $\mathrm{pH}$ in the hemolymph. In type II insects, paralysis symptoms are limited to gut movement. Paralysis is thought to be caused by the breakdown of the epithelial integument, thereby inhibiting function and movement [145]. Gut paralysis in Type II insects has been described as cessation of feeding, frass production, or microscopic evidence of muscles surrounding the gut relaxing (Table 2).

Very few studies have discussed the potential role of the insect nervous system, brain, or neuromuscular junction in insect gut or whole body paralysis. Peristalsis in Lepidoptera is controlled by the stomatogastric nervous system [146]. The frontal ganglion controls the ability of the foregut to empty food into the midgut. Peristalsis is controlled by the frontal connectives so if digestion has ceased then this aspect of the nervous system may have been targeted. However, larva regurgitation is a common defense response during ingestion of plant defense molecules. Midgut paralysis, the cessation of muscles emptying food from the foregut to the midgut, causing regurgitation, is not usually distinguished from regurgitation as a defense response. The toxins of insect pathogens which have both oral and injectable toxicity could selectively silence specific insect nervous tissues surrounding digestion and midgut muscle movement. Understanding toxins of this nature would help determine the function of these tissues in insect behavior, especially regarding food consumption.

One Cry toxin of Bt, CrylC, targets the nervous system [28] and the gut [147] of various Lepidoptera species. Although Cry toxins are orally toxic compounds acting as gut poisons, upon observing a range of gut paralytic effects the role of the nervous system has been discussed [148]. 
Some of the neurotoxic effects of Cry toxins may be explained by their homology to both Pir toxin from $P$. luminescens and neurotoxin from L. decemlineata [56].

\subsubsection{Neurotoxicity in Other Bt Strains}

Neurotoxic symptoms have been observed when Bt var. israelensis (Bti) are directly injected into T. ni. Higher doses of Bti stops heart activity when injected into the hemolymph. Moreover, a loss of motor activity, paralysis and flaccidity was observed. Similar but more benign symptoms occurred when Bti was injected into mice. Oral feeding of Bt kurstaki strain to T. ni resulted in vomiting while injection had no adverse neuromuscular affects. The proteins conferring neurotoxicity were components of the crystal endotoxin from Bti [149].

The neurotoxic effects of Bti were further explored in the American cockroach, Periplaneta americana (Blattodea: Blattidae). The presynaptic nerve terminal function was suspected to be blocked whereas the postsynaptic membranes and axons in the ventral nerve cord remained unaffected. The sixth abdominal ganglion transmitter release, calcium uptake, and complete blockage of transmitters were observed. Rat muscle cultures treated with a purified crystal protein from Bti resulted in degeneration. The mode of action described was related to $\mathrm{Na}^{+} / \mathrm{K}^{+}$-ATPase damage upon incubation and $\mathrm{K}^{+}$levels decrease while $\mathrm{Na}^{+}$levels increase within muscles cells with increasing $\mathrm{Ca}^{2+}$ influx [150].

Table 2. Paralytic effects of ingested Bt on various lepidopteran families and species.

\begin{tabular}{|c|c|c|c|}
\hline Family & Species & Bt component & Response \\
\hline \multirow[t]{3}{*}{ Noctuidae } & Spodoptera spp. & Not specified & No paralysis \\
\hline & H. virescens & Bt var. kurstaki & $\begin{array}{l}\text { Midgut paralysis; Intermittent whole body paralysis with } \\
\text { recovery to body paralysis }\end{array}$ \\
\hline & T. $n i$ & Not specified & Type I paralysis \\
\hline Saturniidae & Philosamia ricini & Bt var. sotto crystals & Whole body paralysis, Type I \\
\hline Crambidae & Ostrinia nubilalis & Bt var. thuringiensis crystalline paraspores & Gut paralysis \\
\hline \multirow[t]{3}{*}{ Pyralidae } & Not specified & Cry proteins & Paralysis \\
\hline & G. mellonella & Spores and crystals derived from Thuricide & No paralysis, Type III most susceptible to spores \\
\hline & Ephestia cautella & Not specified & Type II paralysis \\
\hline Sphingidae & $\begin{array}{c}\text { Phlegathontius } \\
\text { quinquemaculatus }\end{array}$ & $\begin{array}{l}\text { Thuricide (International Minerals and } \\
\text { Chemical Corp., Libertyville, IL, USA) }\end{array}$ & $\begin{array}{l}\text { Abnormally quiescent, cessation of feeding and slow death, } \\
\text { no paralytic effect which was directly compared to synthetic } \\
\text { insecticide induce paralysis }\end{array}$ \\
\hline Erebidae & L. dispar & Not specified & Type II paralysis \\
\hline \multirow[t]{2}{*}{ Plutellidae } & P. xylostella & Bt biological products & Decreased movement with subsequent paralysis \\
\hline & P. xylostella & $\begin{array}{l}\text { Bt var. kurstaki-HD1, sprayed bacterial } \\
\text { suspensions }\end{array}$ & $\begin{array}{l}\text { Reduction of movements to stoppage, limp, loss of agility } \\
\text { and movements slow, unresponsive to touch }\end{array}$ \\
\hline Papilionidae & Papilio demoleus & Bti Berliner spore & $\begin{array}{l}\text { Fairly rapid paralysis followed by an increase of blood } \\
\text { alkalinity after ingestion of spores }\end{array}$ \\
\hline Gelechiidae & Pectinophora gossypella & Bt $\delta$-endotoxin & $\begin{array}{c}\text { Evidence of gut paralysis by histological investigation } \\
\text { where gut muscles surrounding the disorganized epithelium } \\
\text { are relaxed }\end{array}$ \\
\hline
\end{tabular}


Table 2. Cont.

\begin{tabular}{|c|c|c|c|}
\hline Family & Species & Bt component & Response \\
\hline \multirow[t]{7}{*}{ Bombycidae } & B. mori & Bacillus sotto & Paralysis within four hours \\
\hline & B. mori & Bt var. sotto & Paralysis \\
\hline & B. mori & Not specified & Type I paralysis \\
\hline & $\begin{array}{c}\text { Protoparce } \\
\text { quinquemaculata }\end{array}$ & $\mathrm{Bt}$ & General paralysis \\
\hline & P. quinquemaculata & Not specified & Type I paralysis \\
\hline & Protoparce sexta & Bt crystals & General paralysis \\
\hline & Antheraea pernyi & Bt crystals & General paralysis \\
\hline \multirow[t]{2}{*}{ Pieridae } & Colias eurytheme & Bt var. thuringiensis & No paralysis \\
\hline & Pieris rapae & Not specified & Type II paralysis \\
\hline Hesperiidae & Urbanus acawoios & Bt var. kurstaki wettable powder & $\begin{array}{c}\text { Decreased movement after } 10 \mathrm{~h} \text {, classified as likely Type II } \\
\text { because no general paralysis }\end{array}$ \\
\hline Tortricidae & $\begin{array}{l}\text { Choristoneura } \\
\text { fumiferana }\end{array}$ & Bt Dipel foliar spray & $\begin{array}{l}\text { Interruption of feeding due to gut paralysis resulted in } \\
\text { reducing rate of development }\end{array}$ \\
\hline
\end{tabular}

\section{Areas for Future Study}

The recent discoveries of numerous insect toxin analogs have raised questions about the origin of virulence factor genes of entomopathogenic bacteria. This is because it is those genes which define the very nature of entomopathogens and their pathogenic relationships with their target hosts. There are also symptoms which occur in entomopathogenicity which have no defined virulence factor associated, raising the question of who is the culprit. This section addresses some of these questions and briefly summarizes the work that has been done to raise these questions.

\subsection{Why Are There so Many Insecticidal Genes in Bacteria?}

One potential answer to the question of why there are so many insecticidal genes lies in the nature of Lepidopteran larvae behavior. Many larval stages spend most of their time ingesting food and bacteria along with it. Bacteria exist in habitats where these insects reside such as soil, phylloplane, or in an endophytic stage. Therefore, it is no surprise that potent virulence factors of entomopathogenic bacteria have an oral route for toxicity, like the Tc superfamily and Cry toxins.

The gut of lepidopteran larvae is also a reservoir of diverse bacterial populations that interact with one another, competing for both space and nutrients. It is known that organisms in constant competition for resources are in an atmosphere which fosters adaptation [151]. For example, $P$. luminescens has adapted to outcompete surrounding microbes by secreting antibiotics. As a result, after infecting an insect host, $P$. luminescens dominates the insect cadaver [152].

Previous to molecular genome comparisons, bacteria were categorized by their specific pathogenic effect. For example species within the $B$. cereus sensu lato are distinguished by the diseases they cause in humans and insects. Now we come to find through bioinformatic analysis that similar insecticidal toxins have been identified in their genomes. The high degree of similarity between genomes of different Bacillus spp. and the identification of common insecticidal genes is probably due to plasmid shuffling, horizontal gene transfer events, and phage elements surrounding the toxin genes. It can be 
hypothesized that these similarities could be explained by their shared environment, including a common host, which promoted the exchange of genetic material. For example, recent genome analysis of Yersinia and Serratia have shown evidence of similar plasmid shuffling events in Y. pseudotuberculosis [153] and transposable elements in S. entomophila [154].

As more bacterial genomes are sequenced, more virulence factors will be identified between different taxa. So far, analogs within the $t c$ gene superfamily, originally identified in P. luminescens, have also been identified in Yersinia, Xenorabdus, Bacillus, Clostridium, Salmonella and Serratia [155] potentially with more to come. Photorhabdus Pir proteins have homology to Bt Cry toxins and Mcf toxins have analogs in both Clostridium and Pseudomonas [56].

\subsection{Why Nematode-Vectored Entomopathogenic Bacteria that Are Directly Delivered to the Host's}

Hemocoel Produce Oral Toxins?

Photorhabdus luminescens toxins have both oral and hemolymph-based toxic capability. Hemolymph-based toxicity from an insect pathogen which can be delivered directly into the insect makes sense but the orally toxic nature of specific and highly pathogenic toxins is curious. The $t c$ genes are found in many organisms which are not directly delivered into the hemolymph. The origin of the $t c$ genes could be better understood by investigating the ancestry of bacteria with Tc toxins and the origins of nematode association with bacteria.

\subsection{Why Is the Mechanism of Gut Paralysis Limited to Bt?}

As mentioned above, Bt toxins are known to cause gut and whole body paralysis. It has been demonstrated that $\mathrm{Bt}$ causes whole body paralysis by the release of $\mathrm{K}^{+}$from the compromised midgut into the hemolymph or from intracellular sources such as $\mathrm{K}^{+}$channels, in the absence of midgut $\mathrm{K}^{+}$[156]. Paralysis effects can be mimicked, by injecting alkaline buffers directly into the hemocoel [145]. Most neurotoxins, in particular those derived from insect hunting arthropods (i.e., spiders), act on major ion channels to produce their paralyzing effect [157]. Bt has been previously reported to disrupt ion channels in the midgut $[158,159]$ and ion channel formation at gut neuromuscular junctions could be one way Bt causes paralysis. The binding of Bt to ATP binding cassettes also has the potential to disrupt ion transport across a membrane. ATP binding cassettes utilize ATP to transport various substrates across membranes and have recently been identified as Bt receptors. Insects harboring mutant ATP binding cassettes in their genome are resistant to Bt. This may be another mechanism to investigate regarding Bt gut paralysis.

\section{Conclusions}

Without any doubt, Bt, whether incorporated into a foliar spray or toxins expressed in transgenic plants, is regarded as the premier entomopathogen used in insect pest management. Recently, similar toxins to that of $\mathrm{Bt}$ have been identified throughout the bacterial kingdom. These finding may have two types of implications: (1) the development of novel tools for insect pest management and (2) the gain of further knowledge of the origin of entomopathogens and their associated virulence factors. For example, it would be interesting to investigate if the combination of virulence factors of two different 
entomopathogenic bacteria such as Photorhabdus and Bacillus delay resistance. Combining toxins with different modes of action may delay the onset of resistance by forcing insects to develop two separate mechanisms of resistance. Moreover, their combination could result in a more lethal insecticide that would result in a better control tactic for a problematic insect pest.

Furthermore, the delivery mechanism of Photorhabdus, i.e., directly released by nematodes into the insect's hemocoel, suggests the existence of virulence factors with novel tissue targets in the Lepidoptera that can be further investigated. If proven successful the combination of newly identified hemolymph-based toxins with conventional orally-based toxins would expand their application in insect pest management.

Entomopathogens in general have a history of horizontal gene transfer events shuffling toxin-containing plasmids and pathogenicity islands between each other. The acquisition of insecticidal genes may be a strategy that developed to onset virulence once bacteria were ingested, thereby, broadening the availability of possible nutrient sources. Recognizing that insect virulence factor genes are present throughout the bacterial kingdom can broaden our knowledge of the nature of entomopathogenicity and the role of bacterial symbionts as entomopathogenic partners.

\section{Acknowledgments}

The authors would like to acknowledge the Postdoctoral Program for Excellence in Research and Teaching (PERT) at The University of Arizona Center for Insect Science, funding through the National Institute of Health training grant number 1K12 GM 00708, IRACDA Program, for supporting A. Castagnola during the time of the writing of this manuscript. We also acknowledge funding from NEMASYM (Nematode-Bacterium Symbioses) Research Coordination Network (NSF-IOS 0840932 to S. P. Stock).

The opinions shared in this manuscript are not necessarily a reflection of those of the National Institute of Health or the National Science Foundation.

\section{Conflicts of Interest}

The authors declare no conflict of interest.

\section{References}

1. Steinhaus, E.A. Living insecticides. Sci. Am. 1956, 195, 96-106.

2. Lacey, L.A.; Frutos, R.; Kaya, H.K. Insect pathogens as biological control agents: Do they have a future? Biol. Contr. 2001, 21, 230-248.

3. Lacey, L.A.; Kaya, H.K. Field Manual of Techniques in Invertebrate Pathology, 2nd ed.; Springer: Dorcrecht, The Netherlands, 2007.

4. Kaya, H.K.; Vega, F.E. Insect Pathology, 2nd ed.; Elsevier Academic Press: San Diego, CA, USA, 2012.

5. Ishiwata, S.C. One kind of severe flacherie (sotto disease). Dainihon Sans Kaiho 1901, 114, 1-5.

6. Berliner, E. Ueber die schlaffsucht der ephestia kuhniella und Bacillus thuringiensis n. sp. Z Angew. Entomology 1915, 2, 21-56 (in German). 
7. Wilcox, D.R.; Shivakumar, A.G.; Melin, B.E. Genetic Engineering of Bioinsecticides. In Protein Engineering Applications in Science, Medicine, and Industry, 1st ed.; Inouye, M., Sarma, R., Eds.; Academic Press: Orlando, FL, USA, 1986; pp. 395-412.

8. Fischhoff, D.A.; Bowdish, K.S.; Perlak, F.J. Insect tolerant transgenic tomato plants. Nat. Biotechnol. 1987, 5, 807-813.

9. Hilder, V.A.; Gatehouse, A.M.; Sheerman, S.E. A novel mechanism of insect resistance engineered into tobacco. Nature 1987, 330, 160-163.

10. Watkins, P.R.; Huesing, J.E.; Margam, V. Insects, Nematodes, and Other Pests. In Plant Biotechnology and Agriculture Prospects for the 21st Century, 1st ed.; Altman, A., Hasegawa, P.M., Eds.; Elsevier: London, UK, 2012; pp. 353-370.

11. Gatehouse, J.A. Biotechnological prospects for engineering insect-resistant plants. Plant Physiol. 2008, 146, 881-887.

12. Chattopadhyay, A.; Bhatnagar, N.B.; Bhatnagar, R. Bacterial insecticidal toxins. Crit. Rev. Microbiol. 2004, 30, 33-54.

13. Priest, F.G.; Barker, M.; Baillie, L.W. Population structure and evolution of the Bacillus cereus group. J. Bacteriol. 2004, 186, 7959-7970.

14. Ochman, H.; Lawrence, J.G.; Groisman, E.A. Lateral gene transfer and the nature of bacterial innovation. Nature 2000, 405, 299-304.

15. Nielsen-LeRoux, C.; Gaudriault, S.; Ramarao, N. How the insect pathogen bacteria Bacillus thuringiensis and Xenorhabdus/Photorhabdus occupy their hosts. Curr. Opin. Microbiol. 2012, 15, 220-231.

16. Shelton, A.M.; Zhao, J.Z.; Roush, R.T. Economic, ecological, food safety, and social consequences of the deployment of Bt transgenic plants. Annu. Rev. Entomol. 2002, 47, 845-881.

17. Höfte, H.; Whiteley, H.R. Insecticidal crystal proteins of Bacillus thuringiensis. Microbiol. Rev. 1989, 53, 242-255.

18. Gough, J.M.; Akhurst, R.J.; Ellar, D.J. New isolates of Bacillus thuringiensis for control of livestock ectoparasites. Biol. Contr. 2002, 23, 179-189.

19. Chilcott, C.N.; Ellar, D.J. Comparative toxicity of Bacillus thuringiensis var. israelensis crystal proteins in vivo and in vitro. J. Gen. Microbiol. 1988, 134, 2551-2558.

20. Kreig, A.; Huger, A.M.; Langenbruch, G.A. New results on Bacillus thuringiensis var tenebrionis with special regard to its effect on the colorado beetle (Leptinotarsa decemlineata). Anz Schadlingskunde Pflanzenschutz Umweltschutz 1984, 57, 145-150.

21. Rose, E.A.; Harris, R.J.; Glare, T.R. Possible pathogens of social wasps (Hymenoptera: Vespidae) and their potential as biological control agents. New Zeal. J. Zool. 1999, 26, 179-190.

22. Wei, J.Z.; Hale, K.; Carta, L.; Plazter, E.; Wong, C.; Fang, S.C.; Aroian, R.V. Bacillus thuringiensis crystal proteins that target nematodes. Proc. Natl. Acad. Sci. USA 2003, 100, 2760-2765.

23. Hui, F.; Scheib, U.; Hu, Y. Structure and glycolipid binding properties of the nematicidal protein Cry5B. Biochemistry 2012, 51, 9911-9921.

24. Schnepf, E.; Crickmore, N.; van Rie, J. Bacillus thuringiensis and its pesticidal crystal proteins. Microbiol. Mol. Biol. Rev. 1998, 62, 775-806. 
25. Loeb, M.J.; Martin, P.A.; Hakim, R.S. Regeneration of cultured midgut cells after exposure to sublethal doses of toxin from two strains of Bacillus thuringiensis. J. Insect. Physiol. 2001, 47, 599-606.

26. Griego, V.M.; Fanchier, L.J.; Spence, K.D. Scanning electron microscopy of the disruption of tobacco hornworm, Manduca sexta, midgut by Bacillus thuringiensis, endotoxin. J. Invertebr. Pathol. 1980, 35, 186-189.

27. Bravo, A.; Jansens, S.; Peferoen, M. Immunocytochemical localization of Bacillus thuringiensis insecticidal crystal proteins in intoxicated insects. J. Invertebr. Pathol. 1992, 60, 237-246.

28. Cerstiaens, A.; Verleyen, P.; van Rie, J. Effect of Bacillus thuringiensis Cry1 toxins in insect hemolymph and their neurotoxicity in brain cells of Lymantria dispar. Appl. Environ. Microb. 2001, 67, 3923-3927.

29. Haider, M.Z.; Ellar, D.J. Mechanism of action of Bacillus thuringiensis insecticidal $\delta$-endotoxin: Interaction with phospholipid vesicles. Biochim. Biophys. Acta 1989, 978, 216-222.

30. Zhang, X.; Candas, M.; Griko, N.B. A mechanism of cell death involving an adenylyl cyclase/PKA signaling pathway is induced by the CrylAb toxin of Bacillus thuringiensis. Proc. Natl. Acad. Sci. USA 2006, 103, 9897-9902.

31. Tanaka, S.; Miyamoto, K.; Noda, H. The ATP-binding cassette transporter subfamily C member 2 in Bombyx mori larvae is a functional receptor for cry toxins from Bacillus thuringiensis. FEBS J. 2013, 280, 1782-1794.

32. Atsumi, S.; Miyamoto, K.; Yamamoto, K. A single amino acid mutation in an ABC transporter causes resistance to Bt toxin Cryl Ab in the silkworm, Bombyx mori. Proc. Natl. Acad. Sci. USA Plus 2012, 109, E1591-E1598.

33. Gahan, L.J.; Pauchet, Y.; Vogel, H. An ABC transporter mutation is correlated with insect resistance to Bacillus thuringiensis Cry1 Ac toxin. PLoS Genet. 2010, 6, e1001248.

34. Baxter, S.W. Parallel evolution of Bacillus thuringiensis toxin resistance in lepidoptera. Genetics 2011, 189, 675-679.

35. Arneson, L.P.; Fagerlund, A.; Granum, P.E. From soil to gut: Bacillus cereus and its food poisoning toxins. FEMS Microbiol. Rev. 2008, 32, 579-606.

36. Perchat, S.; Buisson, C.; Chaufaux, J. Bacillus cereus produces several nonproteinaceous insecticidal exotoxins. J. Invertebr. Pathol. 2005, 90, 131-133.

37. Zwick, M.E.; Joseph, S.J.; Didelot, X. Genomic characterization of the Bacillus cereus sensu lato species: Backdrop to the evolution of Bacillus anthracis. Genome Res. 2012, 22, 1512-1524.

38. Singer, S. The Utility of Strains of Morphological Group II Bacillus. In Advances in Applied Microbiology; Academic Press: San Diego, CA, USA, 1996; Volume 42, pp. 219-259.

39. Berry, C. The bacterium, Lysinibacillus sphaericus, as an insect pathogen. J. Invertebr. Pathol. 2012, 109, 1-10.

40. Nishiwaki, H.; Nakashima, K.; Ishida, C. Cloning, functional characterization and mode of action of a novel insecticidal pore-forming toxin, Sphaericolysin, produced by Bacillus sphaericus. Appl. Environ. Microb. 2007, 73, 3404-3411.

41. Barth, H.; Aktories, K.; Popoff, M.; Binary bacterial toxins: Biochemistry, biology, and applications of common Clostridium and Bacillus proteins. Microbiol. Mol. Biol. Rev. 2004, 68, 373-402. 
42. Nicolas, L.; Charles, J.F.; Debarjac, H. Clostridium bifermentans servovar malaysia; characterization of putative mosquito larvicidal proteins. FEMS Microbiol. Lett. 1993, 113, 23-29.

43. Tsuge, H.; Nagahama, M.; Nishimura, H. Crystal structure and site-directed mutagenesis of enzymatic components from Clostridium perfringens iota-toxin. J. Mol. Biol. 2003, 325, 471-483.

44. Just, I.; Gerhard, R. Large clostridial cytotoxins. Rev. Physiol. Biochem. Pharmacol. 2005, 152, 23-47.

45. Aktories, K.; Schwan, C.; Papatheodorou, P. Bidirectional attack on the actin cytoskeleton. bacterial protein toxins causing polymerization or depolymerization of actin. Toxicon 2012, 60, $572-581$.

46. Visschedyk, D.D.; Perieteanu, A.A.; Turgeon, Z.J. Photox, a novel actin-targeting mono-ADP-ribosyltransferase from Photorhabdus luminescens. J. Biol. Chem. 2010, 285, 13525-13534.

47. Fischer-Le Saux, M.; Viallard, V. Spodoptera littoralis Photorhabdus and proposal of new taxa: P. luminescens subsp. luminescens subsp. nov., P. luminescens subsp. akhurstii subsp. nov., $P$. luminescens subsp. laumondii subdp. nov., P. temperata sp. nov. and $P$. asymbiotica sp. nov. Int. J. Syst. Bacteriol. 1999, 49, 1645-1656.

48. Gerrard, J.G.; Joyce, S.A.; Waterfield, N.R. Nematode symbiont for Photorhabdus asymbiotica. Emerg. Infect. Dis. 2006, 12, 1562-1564.

49. Gerrard, J.; Waterfield, N.; Vohra, R. Human infection with Phtotorhabdus asymbiotica: An emerging bacterial human pathogen. Microbes Infect. 2004, 6, 229-237.

50. Duchaud, E.; Rusniok, C.; Frangeul, L. The genome sequence of the entomopathogenic bacterium Photorhabdus luminescens. Nat. Biotechnol. 2003, 21, 1307-1313.

51. Rodou, A.; Ankrah, D.; Stathopoulos, C. Toxins and secretion systems of Photorhabdus luminescens. Toxins 2010, 2, 1250-1264.

52. Daborn, P.J.; Waterfield, N.; Silva, C.P. A single Photorhabdus gene, makes caterpillars floppy (mcf), allows Escheria coli to persist within and kill Insects. Proc. Natl. Acad. Sci. USA 2002, 99, 10742-10747.

53. Waterfield, N.; Hares, M.; Yang, G. Potentiation and cellular phenotypes of the insecticidal toxin complexes of Photorhabdus bacteria. Cell. Microbiol. 2005, 7, 373-382.

54. Waterfield, N.; Kamita, S.G.; Hammock, B.D. The Photorhabdus Pir toxins are similar to a developmentally regulated insect protein but show no juvenile hormone esterase activity. FEMS Microbiol. Lett. 2005, 245, 47-52.

55. Blackburn, M.B.; Farrar, R.R.; Novak, N.G. Remarkable susceptibility to the diamondback moth (Plutella xylostella) to ingestion of Pir toxins from Photorhabdus luminescens. Entomol. Exp. Appl. 2006, 121, 31-37.

56. Ffrench-Constant, R.H.; Dowling, A.; Waterfield, N. Insecticidal toxins from Photorhabdus bacteria and their potential use in agriculture. Toxicon 2007, 49, 436-451.

57. Crosland, R.; Fitch, R.; Hines, H. Characterization of beta-leptinotarsin and the effects of calcium flux antagonists on its activity. Toxicon 2005, 45, 829-841.

58. Brown, S.E.; Cao, A.T.; Dobson, P. Txp40, a ubiquitous insecticidal toxin protein from Xenorhabdus and Photorhabdus bacteria. Appl. Environ. Microb. 2006, 72, 1653-1662. 
59. Park, J.M.; Kim, M.; Min, J. Proteomic identification of a novel toxin protein (Txp40) from Xenorhabdus nematophila and its insecticidal activity against larvae of Plutella xylostella. J. Agric. Food Chem. 2012, 60, 4053-4059.

60. Brown, S.E.; Cao, A.T.; Hines, E.R.; Akhurst, R.J.; East, P.D. A novel secreted protein toxin from the insect pathogenic bacterium Xenorhabdus nematophila. J. Biol. Chem. 2004, 279, 14595-14601.

61. Sicard, M.; Le Brun, N.; Pages, S. Effect of native Xenorhabdus on the fitness of their Steinernema hosts: Contrasting types of interaction. Parasitol. Res. 2003, 91, 520-524.

62. Singh, P.; Park, D.; Forst, S. Xenocin export by the flagellar type III pathway in Xenorhabdus nematophila. J. Bacteriol. 2013, 195, 1400-1410.

63. Sergeant, M.; Jarrett, P.; Ousley, M. Interactions of insecticidal toxin gene products from Xenorhabdus nematophilus PMFI296. Appl. Environ. Microb. 2003, 69, 63344-63349.

64. Pan, Y.; Jian, H.; Zhang, J. An intracellular toxic protein (Xin) isolated from Xenorhabdus nematophilus strain BJ. Prog. Nat. Sci. 2002, 12, 310-312.

65. Vigneux, F.; Zumbihl, R.; Jubelin, G. The $x a x A B$ genes encoding a new apoptotic toxin from the insect pathogen Xenorhabdus nematophila are present in plant and human pathogens. J. Biol. Chem. 2007, 282, 9571-9580.

66. Viitanen, P.V.; Gatenby, A.A.; Lorimer, G.H. Purified chaperonin 60 (groEL) interacts with the nonnative states of a multitude of Escherichia coli proteins. Protein Sci. 1992, 1, 363-369.

67. Ellis, J.R. Chaperomics: In vivo GroEL function defined. Curr. Biol. 2005, 15, R661-R663.

68. Yang, J.; Zeng, H.M.; Lin, H.F. An insecticidal protein from Xenorhabdus budapestensis that results in prophenoloxidase activation in the wax moth, Galleria mellonella. J. Invertebr. Pathol. 2012, 110, 60-67.

69. Lamelas, A.; Gosalbes, M.J.; Manzano-Marín, A. Serratia symbiotica from the aphid Cinara cedri: A missing link from facultative to obligate insect endosymbiont. PLoS Genet. 2011, 7, 1-11.

70. Rae, R.; Riebesell, M.; Dinkelacker, I. Isolation of naturally associated bacteria of necromenic Pristionchus nematodes and fitness consequences. J. Exp. Biol. 2008, 211, 1927-1936.

71. Abebe, E.; Abebe-Akele, F.; Morrison, J. An insect pathogenic symbiosis between a caenorhabditis and serratia. Virulence 2011, 2, 158-161.

72. Jackson, T.A.; Boucias, D.G.; Thaler, J.O. Pathobiology of amber disease, caused by Serratia spp., in the New Zealand grass grub, Costelytra zealandica. J. Invertebr. Pathol. 2001, 78, 232-243.

73. Sikorowski, P.P.; Lawrence, A.M.; Inglis, G.D. Effects of Serratia marcescens on rearing of the tobacco budworm (Lepidoptera: Noctuidae). Am. Entomol. 2001, 47, 51-60.

74. Hurst, M.R.H.; Glare, T.R.; Jackson, T.A.; Ronson, C.W. Plasmid-located pathogenicity determinants of Serratia entomophila, the causal agent of amber disease of grass grub, show similarity to the insecticidal toxins of Photorhabdus luminescens. J. Bacteriol. 2000, 182, 5127-5138.

75. Hurst, M.R.; Beard, S.S.; Jackson, T.A. Isolation and characterization of the Serratia entomophila antifeeding prophage. FEMS Microbiol. Lett. 2007, 270, 42-48.

76. Dodd, S.J.; Hurst, M.R.; Glare, T.R. Occurrence of sep insecticidal toxin complex genes in Serratia spp. and Yersinia frederiksenii. Appl. Environ. Microb. 2006, 72, 6584-6592. 
77. Tennant, S.M.; Skinner, N.A.; Joe, A. Homologues of insecticidal toxin complex genes in Yersinia enterocolitica biotype 1A and their contribution to virulence. Infect. Immun. 2005, 73, 6860-6867.

78. Fuchs, T.M.; Bresolin, G.; Marcinowski, L. Insecticidal genes of Yersinia spp.: Taxonomical distribution, contribution to toxicity towards Manduca sexta and Galleria mellonella, and evolution. BMC Microbiol. 2008, 8, 1-11.

79. Parkhill, J.; Wren, B.W.; Thomson, N.R. Genome sequence of Yersinia pestis, the causitive agent of plague. Nature 2001, 413, 523-527.

80. Bresolin, G.; Morgan, J.A.; Illgen, D. Low temperature-induced insecticidal activity of Yersinia enterocolitica. Mol. Microbiol. 2006, 59, 503-512.

81. Spanier, B.; Starke, M.; Higel, F. Yersinia enterocolitica infection and tcaA-dependent killing of Ceaenorhabditis elegans. Appl. Environ. Microb. 2010, 76, 6277-6285.

82. Hurst, M.R.; Jones, S.A.; Binglin, T. The main virulence determinant of Yersinia entomophaga MH96 is a broad-host-range toxin complex active against insects. J. Bacteriol. 2011, 193, 1966-1980.

83. Péchy-Tarr, M.; Bruck, D.J.; Maurhofer, M. Molecular analysis of a novel gene cluster encoding an insect toxin in plant-associated strains of Pseudomonas fluorescens. Environ. Microbiol. 2008, 10, 2368-2386.

84. Ruffner, B.; Péchy-Tarr, M.; Ryffel, F. Oral insecticidal activity of plant-associated pseudomonads. Environ. Microbiol. 2013, 3, 751-763.

85. Hassan, K.A.; Johnson, A.; Shaffer, B.T. Inactivation of the GacA response regulator in Pseudomonas fluorescens Pf-5 has far-reaching transcriptomic consequences. Environ. Microbiol. 2010, 12, 899-915.

86. Vodovar, N.; Vallenet, D.; Cruveiller, S. Complete genome sequence of the entomopathogenic and metabolically versatile soil bacterium Pseudomonas entomophila. Nat. Biotechnol. 2006, 24, 673-679.

87. Margo, G.; Porcar, M. Ecological mysteries: Is Bacillus thuringiensis a real insect pathogen? Bt Res. 2012, 3, 1-2.

88. Yuan, Y.M.; Hu, X.M.; Liu, H.Z. Kinetics of plasmid transfer among Bacillus cereus group strains within lepidopteran larvae. Arch. Microbiol. 2007, 187, 425-431.

89. Hu, X.M.; Mahillon, J. Life Cycle and Gene Exchange. In Endospore-forming Soil Bacteria, 1st ed.; Logan, N.A., DeVos, P., Eds.; Springer-Verlag Berlin: Berlin, Germany, 2011; Volume 27, pp. 89-113.

90. Mohan, M.; Selvakumar, G.; Sushil, S.N. Entomopathogenicity of endophytic Serratia marcescens strain SRM against larvae of Helicoverpa armigera (Noctuidae: Lepidoptera). World J. Microb. Biotechnol. 2011, 27, 2545-2551.

91. Boucher, Y.; Douady, C.J.; Papke, R.T. Lateral gene transfer and the origins of prokaryotic groups. Annu. Rev. Genet. 2003, 37, 283-328.

92. Andersson, J.O. Lateral gene transfer in eukaryotes. Cell. Mol. Life Sci. 2005, 62, 1182-1197.

93. Acuna, R.; Padilla, B.E.; Florez-Ramos, C.P. Adaptive horizontal gene transfer of a bacterial gene to an invasive insect pest of coffee. Proc. Natl. Acad. Sci. USA 2012, 109, 4197-4202. 
94. Pauchet, Y.; Heckel, D.G. The genome of the mustard leaf beetle encodes two active xylanases originally acquired from bacteria through horizontal gene transfer. Proc. R. Soc. B Biol. Sci. 2013, 280, 1-7.

95. Wheeler, D.; Redding, A.J.; Werren, J.H. Characterization of an ancient lepidopteran lateral gene transfer. PLoS One 2013, 8, 1-9.

96. Wybouw, N.; Balabanidou, V.; Ballhorn, D.J. A horizontally transferred cyanase gene in the spider mite Tetranychus urticae is involved in cyanate metabolism and is differentially expressed upon host plant change. Insect Biochem. Mol. 2012, 42, 881-889.

97. Thomas, D.J.; Morgan, J.A.; Whipps, J.M. Plasmid transfer between Bacillus thuringiensis subsp. israelensis strains in laboratory culture, river water, and dipteran larvae. Appl. Environ. Microb. 2001, 67, 330-338.

98. Blackburn, M.B.; Martin, P.A.; Kuhar, D.; Farrar, R.R., Jr.; Gundersen-Rindal, D.E. The Occurrence of Photorhabdus-Like Toxin Complexes in Bacillus thuringiensis. PLoS One 2011, 6, doi:10.1371/journal.pone.0018122.

99. Chen, G.; Zhang, Y.; Li, J. Chinitase activity of Xenorhabdus and Photorhabdus species, bacterial associates of entomopathogenic nematodes. J. Invertebr. Pathol. 1996, 68, 101-108.

100. Cabral, C.M.; Cherqui, A.; Pereira, A. Purification and characterization of two distinct metalloproteases secreted by the entomopathogenic bacterium Photorhabdus sp strain Az29. Appl. Environ. Microb. 2004, 70, 3831-3838.

101. Sergeant, M.; Baxter, L.; Jarret, P. Identification, typing, and insecticidal activity of Xenorhabdus isolates from entomopathogenic nematodes in United Kingdom soil and characterization of the xpt toxin loci. Appl. Environ. Microb. 2006, 72, 5895-5907.

102. Chaston, J.M.; Suen, G.; Tucker, S.L. The entomopathogenic bacterial endosymbionts Xenorhabdus and Photorhabdus: Convergent lifestyles from divergent genomes. PLoS One 2011, 6, e27909.

103. Goodrich-Blair, H.; Clarke, D.J. Mutualism and pathogenesis in Xenorhabdus and Photorhabdus: Two roads to the same destination. Mol. Microbiol. 2007, 64, 260-268.

104. Bowen, D.J.; Ensign, J.C. Purification and characterization of a high-molecular-weight insecticidal protein complex produced by the entomopathogenic bacterium Photorhabdus luminescens. Appl. Environ. Microb. 1998, 64, 3029-3035.

105. Waterfield, N.; Dowling, A.; Sharma, S. Oral toxicity of Photorhabdus luminescens W14 toxin complexes in Escherichia coli. Appl. Environ. Microbiol. 2001, 67, 5017-5024.

106. Liu, D.; Burton, S.; Glancy, T. Insect resistance conferred by 283-kDa Photorhabdus luminescens protein TcdA in Arabidopsis thaliana. Nat. Biotechnol. 2003, 21, 1307-1313.

107. Pinheiro, V.B.; Ellar, D.J. Expression and insecticidal activity of Yersinia pseudotuberculosis and Photorhabdus luminescens toxin complex proteins. Cell. Microbiol. 2007, 9, 2372-2380.

108. Ffrench-Constant, R.; Waterfield, N. An ABC guide to the bacterial toxin complexes. Adv. Appl. Microbiol. 2005, 58, 169-183.

109. Yoshino, E.; Baxter, D.E.; Hsiao, T.H. Release of acetylcholine from rat brain synaptosomes stimulated with leptinotarsin-New neurotoxin. J. Neurochem. 1980, 34, 635-642.

110. McClure, W.O.; Abbott, B.C.; Baxter, D.E. Leptinotarsin-A presynaptic neurotoxin that stimulates release of acetylcholine. Proc. Natl. Acad. Sci. USA 1980, 77, 1219-1223. 
111. Shrestha, Y.K.; Lee, K. Oral toxicity of Photorhabdus culture media on gene expression of the adult sweetpotato whitefly, Bemisia tabaci. J. Invertebr. Pathol. 2012, 109, 91-96.

112. Hurst, M.R.; Glare, T.R.; Jackson, T.A. Cloning Serratia entomophila antifeeding genes-A putative defective prophage active against the grass grub Costelytra zealandica. J. Bacteriol. 2004, 186, 5116-5128.

113. Yang, G.; Dowling, A.J.; Gerike, U. Photorhabdus virulence cassettes confer injectable insecticidal activity against the wax moth. J. Bacteriol. 2006, 188, 2254-2261.

114. Chavez, C.V.; Jubelin, G.; Courties, G. The cyclomodulin Cif of Photorhabdus luminescens inhibits insect cell proliferation and triggers host cell death by apoptosis. Microbes Infect. 2010, $12,1208-1218$.

115. Wolters, M.; Boyle, E.C.; Lardong, K. Cytotoxic necrotizing factor-Y boosts Yersinia effector translocation by activating Rac. J. Biol. Chem. 2013, 288, 23543-23553.

116. Brugirard-Ricaud, K.; Duchaud, E.; Givaudan, A. Site-specific antiphagocytic function of the Photorhabdus luminescens type III secretion system during insect colonization. Cell. Microbiol. 2004, 7, 363-371.

117. Gendlina, I.; Held, K.G.; Bartra, S.S. Identification and type III-dependent secretion of the Yersinia pestis insecticidal-like proteins. Mol. Microbiol. 2007, 64, 1214-1227.

118. Waterfield, N.; Hares, M.; Hinchliffe, S. The insect toxin complex of Yersinia. Adv. Exp. Med. Biol. 2007, 603, 247-257.

119. Spinner, J.L.; Jarrett, C.O.; LaRock, D.L. Yersinia pestis insecticidal-like toxin complex (Tc) family proteins: Characterization of expression, subcellular localization, and potential role in infection of the flea vector. BMC Microbiol. 2012, 12, 1-14.

120. Odinokov, G.N.; Eroshenko, G.A.; Krasnov, J.M. Analysis of insect toxin complex gene variability of Yersinia pestis and Yersinia pseudotuberculosis strains. Russ. J. Genet. 2011, 47, $10-17$.

121. Hares, M.C.; Hinchliffe, S.J.; Strong, P.C. The Yersinia pseudotuberculosis and Yersinia pestis toxin complex is active against cultured mammalian cells. Microbiol. SGM 2008, 154, 3503-3517.

122. Jeong, H.U.; Mun, H.Y.; Oh, H.K. Evaluation of insecticidal activity of a bacterial strain, Serratia, sp EML-SE1 against diamondback moth. J. Microbiol. 2010, 48, 541-545.

123. Brurberg, M.B.; Nes, I.F.; Eijsink, V.G. Comparative studies of chitinases A and B from Serratia marcescens. Microbiol. UK 1996, 142, 1581-1589.

124. Asano, S.; Suzuki, K.; Hori, H. Synergistic effects of the supernatants from Serratia marcescens culture on larvicidal activity of Bacillus thuringiensis Cry1C toxin against common cutworm, Spodoptera litura. J. Pestic. Sci. 1999, 24, 44-48.

125. Abby, S.S.; Rocha, E.P. The non-flagellar type III secretion system evolved from the bacterial flagellum and diversified into host-cell adapeted sytems. PLoS Genet. 2012, 8, 1-15.

126. Vodovar, N.; Vinals, M.; Liehl, P. Drosophila host defense after oral infection by an entomopathogenic Psuedomonas species. Proc. Natl. Acad. Sci. USA 2005, 102, 11414-11419.

127. Younglai, E.V.; Wu, Y.J.; Foster, W.G. Reproductive toxicology of environmental toxicants: Emerging issues and concerns. Curr. Pharm. Des. 2007, 13, 3005-3019.

128. Werner, I.; Hitzfeld, B. 50 years of exotoxicology since silent spring-A review. Gaia 2012, 21, 217-224. 
129. Davies, T.G.; Field, L.M.; Williamson, M.S. The re-emergence of the bed bug as a nuisance pest: Implications of resistance to the pyrethroid insecticides. Med. Vet. Entomol. 2012, 26, 241-254.

130. Durand, R.; Bouvresse, S.; Berdjane, Z. Insecticide resistance in head lice: Clinical, parasitological, and genetic aspects. Clin. Microbiol. Infect. 2012, 18, 338-344.

131. Ranson, H.; N'Guessan, R.; Lines, J. Pyrethroid resistance in African anopheline mosquitoes: What are the implications for malaria control? Trends Parasitol. 2011, 27, 91-98.

132. Knight, A.L. Economics of agricultural pesticide resistance in arthropods. Annu. Rev. Entomol. 1989, 34, 293-313.

133. Mostafalou, S.; Abdollahi, M. Pesticides and human chronic diseases: Evidences, mechanisms, and perspectives. Toxicol. Appl. Pharm. 2013, 268, 157-177.

134. Grue, C.E.; Gibert, P.L.; Seeley, M.E. Neurophysiological and behavioral changes in non-target wildlife exposed to organophosphate and carbamate pesticides: Thermoregulation, food consumption, and reproduction. Am. Zool. 1997, 37, 369-388.

135. Prullage, J.B.; Tran, H.V.; Timmons, P. The combined mode of action of fipronil and amitraz on the motility of Rhipicephalus sanguineus. Vet. Parasitol. 2011, 179, 302-310.

136. Jorens, P.G.; Zandijk, E.; Belmans, L. An unusual poisoning with the unusual pesticide amitraz. Hum. Exp. Toxicol. 1997, 16, 600-601.

137. Marrs, T.C. Toxicology of insecticides to mammals. Pest Manag. Sci. 2012, 68, 1552-1556.

138. Dayan, F.E.; Cantrell, C.L.; Duke, S.O. Natural products in crop protection. Bioorg. Med. Chem. 2009, 17, 4022-4034.

139. Nicholson, G.M. Fighting the global pest problem: Preface to the special toxicon issue on insecticidal toxins and their potential for insect pest control. Toxicon 2007, 49, 413-422.

140. Castagnola, A.; Jurat-Fuentes, J.L. Bt Crops: Past and Future. In Bacillus Thuringiensis Biotechnology, 1st ed.; Sansinenea, E., Ed.; Springer: New York, NY, USA, 2012; Volume 392, pp. 283-304.

141. Windley, M.J.; Herzig, V.; Dziemborowicz, S.A. Spider-venom peptides as bioinsecticides. Toxins 2012, 4, 191-227.

142. Khan, S.A.; Zafar, R.W.; Briddon, K.A. Spider venom toxin protects plants from insect attack. Transgenic Res. 2006, 15, 349-357.

143. Schiavo, G.; Matteoli, M.; Montecucco, C. Neurotoxins affecting neuroexocytosis. Physiol. Rev. 2000, 80, 717-766.

144. Heimpel, A.M.; Angus, T.A. The taxonomy of insect pathogens related to Bacillus cereus frankland and frankland. Can. J. Microbiol. 1958, 4, 531-541.

145. Heimpel, A.M.; Angus, T.A. The site of action of crystalliferous bacteria in lepidopteran larvae. J. Insect Pathol. 1959, 1, 152-170.

146. Hartenstein, V. Development of the insect stomatogastric nervous system. Trends Neurosci. 1997, 20, 421-427.

147. Rodriguez-Cabrera, L.; Trujillo-Bacallao, D.; Borras-Hidalgo, O. Molecular characterization of Spodoptera frugiperda Bacillus thuringiensis CrylCa toxin interaction. Toxicon 2008, 51, 681-692.

148. Aronson, A.I.; Shai, Y. Why Bacillus thuringiensis insecticidal toxins are so effective: Unique features of their mode of action. FEMS Microbiol. Lett. 2001, 195, 1-8. 
149. Cheung, P.Y.; Roe, R.M.; Hammock, B.D. The apparent in vivo neuromuscular effects of the $\delta$-endotoxin of Bacillus thuringiensis var. israelensis in mice and insects of four orders. Pest. Biochem. Physiol. 1985, 23, 85-94.

150. Cahan, R.; Shainberg, A.; Pechatnikov, I. A 28,000 mol. Wt toxin from Bacillus thuringiensis israelensis induces cation transport in rat muscle cultures. Toxicon 1995, 33, 943-951.

151. Münch, A.; Stingl, L.; Jung, K. Photorhabdus luminescens genes induced upon insect infection. BMC Genomics 2008, 9, 1-17.

152. Katrukha, G.S.; Zarubina, A.P.; Iudina, T.P. Antibiotics produced by Photorhabdus luminescens ZMI, a symbiont of entomopathogenic nematodes. Antibiot Khimioter 2009, 54, 11-16.

153. Lesic, B.; Zouine, M.; Ducos-Galand, M. A natural system of chromosome transfer in Yersinia pseudotuberculosis. PLoS Genet. 2012, 8, e1002529.

154. Hurst, M.R.; Becher, S.A.; O'Callaghan, M. Nucleotide sequence of the Serratia entomophila plasmid pADAP and the Serratia proteamaculans pU143 plasmid virulence associated region. Plasmid 2011, 65, 32-41.

155. Ffrench-Constant, R.H.; Bowen, D.J. Novel insecticidal toxins from nematode-symbiotic bacteria. Cell. Mol. Life Sci. 2000, 57, 828-833.

156. Pendleton, I.R. Sodium and potassium fluxes in Philosamia ricini during Bacillus thuringiensis protein crystal intoxication. J. Invertebr. Pathol. 1970, 16, 313-314.

157. Bloomquist, J.R. Ion channels as targets for insecticides. Annu. Rev. Entomol. 1996, 41, 163-190.

158. Fast, P.G.; Angus, T.A. Effects of parasporal inclusions of Bacillus thuringiensis var. sotto ishiwata on the permeability of the gut wall of Bombyx mori (Linnaeus) larvae. J. Invertebr. Pathol. 1965, 7, 29-32.

159. Griego, V.M.; Moffet, D.; Spence, K.D. Inhibition of active $\mathrm{K}^{+}$transport in the tobacco hornworm (Manduca sexta) midgut after ingestion of Bacillus thuringiensis endotoxin. J. Insect Physiol. 1979, 25, 283-288.

(C) 2014 by the authors; licensee MDPI, Basel, Switzerland. This article is an open access article distributed under the terms and conditions of the Creative Commons Attribution license (http://creativecommons.org/licenses/by/3.0/). 